\title{
BMJ Open What are the patient factors that impact on decisions to progress to total knee replacement? A qualitative study involving patients with knee osteoarthritis
}

\author{
Penny O'Brien, ${ }^{\circledR} 1$ Samantha Bunzli, ${ }^{1}$ Darshini Ayton, ${ }^{2}$ Michelle M Dowsey, ${ }^{\circledR 1}$ \\ Jane Gunn, ${ }^{3}$ Jo-Anne Manski-Nankervis ${ }^{\circledR 3}$
}

To cite: O'Brien P, Bunzli S, Ayton D, et al. What are the patient factors that impact on decisions to progress to total knee replacement? A qualitative study involving patients with knee osteoarthritis. BMJ Open 2019;9:e031310. doi:10.1136/ bmjopen-2019-031310

- Prepublication history and additional material for this paper are available online. To view these files, please visit the journal online (http://dx.doi. org/10.1136/bmjopen-2019031310).

Received 27 April 2019

Revised 28 August 2019

Accepted 29 August 2019
Check for updates

(c) Author(s) (or their employer(s)) 2019. Re-use permitted under CC BY-NC. No commercial re-use. See rights and permissions. Published by BMJ.

${ }^{1}$ Department of Surgery, St Vincent's Hospital Melbourne, The University of Melbourne, Melbourne, Victoria, Australia ${ }^{2}$ Monash University, Melboune, Victoria, Australia

${ }^{3}$ Department of General Practice, The University of Melbourne, Melbourne, Victoria, Australia

Correspondence to

Penny O'Brien;

penny.obrien@unimelb.edu.au

\section{ABSTRACT}

Objectives General practitioners (GPs) are often the first health professionals to assess patients with osteoarthritis (OA). Despite clinical guideline recommendations for non-surgical intervention as first-line therapies, the most frequent referral from a GP for a person with knee $0 \mathrm{~A}$ is to an orthopaedic surgeon. The aim of our study was to explore patient factors that impact on the decision to progress to total knee replacement (TKR), including the experience of patients in general practice, their perceptions of their condition, and their access and use of community-based allied health interventions.

Design Qualitative investigation using semi-structured interviews. The Candidacy framework was selected as a lens to examine the factors driving healthcare access. Data were analysed using a thematic analysis approach. Codes identified in the data were mapped to the seven Candidacy domains. Themes corresponding to each domain were described.

Setting A public hospital in Melbourne, Australia. Participants 27 patients with knee OA who were on a waiting list to undergo TKR.

Results Ten themes described factors influencing access and use of non-surgical interventions and decision-making for undergoing TKR: (1) History of knee problems, change in symptoms; (2) Physical and psychosocial functioning (Identification of Candidacy); (3) GP and social networks as information sources, access to care (Navigation); (4) Referral pathways (Permeability of services); (5) Communication of impact (Appearances at health services); (6) GP-Surgeon as the predominant referral pathway (Adjudications); (7) Physical activity as painful; (8) Beliefs about effectiveness of non-surgical interventions (Offers and resistance); (9) Familiarity with local system; and (10) Availability (Operating conditions and local production of Candidacy).

Conclusions Using the Candidacy framework to analyse patients' experiences when deciding to progress to TKR highlighted missed opportunities in general practice to orient patients to first try non-surgical interventions. Patients with knee $\mathrm{OA}$ also require improved support to navigate allied health services.
Strengths and limitations of this study

- The Candidacy framework was utilised to provide a conceptual lens to understand healthcare access for people with knee osteoarthritis (OA), a complex and chronic health condition. We have demonstrated that the Candidacy framework is a useful framework for describing healthcare access beyond that of vulnerable groups for which it was originally designed.

- Qualitative methods enabled us to gain an understanding of the experience of knee $\mathrm{OA}$ in general practice as well as patient factors relating to decision-making for total knee replacement and non-surgical management strategies.

- Participants were recruited from one metropolitan hospital who had already provided consent to undergo knee replacement surgery, and hence may not be representative of the experience of people with $O A$ in the community.

- Approximately half of the participants had a previous total knee replacement which may have impacted on their ability to recall previous experiences and navigate health services.

- The perceptions and experience of health professionals were not explored in this study.

\section{BACKGROUND}

Osteoarthritis (OA) is common, significantly reduces quality of life, and increases mortality and healthcare costs. Compared with the general population, people with $\mathrm{OA}$ are nearly three times more likely to report poor health and have two times the likelihood of high psychological distress and severe pain. ${ }^{1}$ OA accounts for $2.6 \%$ of all general practitioner (GP) consultations in Australia. ${ }^{2}$ It is the second most prevalent chronic condition diagnosed in patients attending general practice, and $\mathrm{OA}$ of the knee is the most common presentation of $\mathrm{OA}^{3}{ }^{4}$ General practice guidelines currently recommend 
self-management and non-surgical interventions (such as exercise, nutritional education and physical therapy) as first-line therapy to reduce pain and maintain function, augmented by pharmacological therapy when required. ${ }^{5}$ Guidelines also recommend that total knee replacement (TKR) only be considered when non-surgical interventions have been ineffective. ${ }^{5}$ Despite this, an Australian study found that the most frequent referral for a person with knee OA from a GP is to an orthopaedic surgeon, rather than allied health professionals for non-surgical interventions. ${ }^{2}$ Data from the UK also indicates that, among patients referred to an orthopaedic surgeon for consideration of hip replacement or TKR, information was not provided on OA, pain management, exercise, and understanding their medication to $58 \%, 65 \%, 57 \%$, and $71 \%$ of participants respectively. ${ }^{6}$

Where patients receive health information and how it is delivered is a critical element in understanding patients' engagement in non-surgical interventions and decision to progress to TKR. Understanding decision-making for, and access to TKR therefore has the potential to improve the quality of information provided to patients in general practice and preoperatively and in turn may help to address the high rates of patient dissatisfaction post-TKR (approximately 17\%). ${ }^{7}$ Evidence suggests that $12 \%$ to $20 \%$ of patients who undergo TKR also do not show clinically relevant improvements. ${ }^{8}$ As the demand for TKR increases with corresponding financial pressure, there is an imperative to develop resources and decision-making tools to assist GPs and patients in their decision to access surgery. ${ }^{7}$

The aim of our study was to explore patient factors that impact on the decision to progress to TKR, including the experience of patients in general practice, their perceptions of their condition and their access and use of community-based allied health interventions.

\section{DESIGN AND FRAMEWORK}

This qualitative study involved semi-structured interviews with patients with knee OA on a TKR waiting list. The conceptual framework of Candidacy was chosen to systematically explore and identify the factors associated with access to TKR. ${ }^{9}$ Rather than focusing on utilisation as a proxy for healthcare access, Candidacy emphasises the complex and contingent nature of healthcare access and has been applied to understand different stages of a patients' healthcare journey by incorporating psychosocial factors which may influence decision-making. ${ }^{10-12}$ The Candidacy framework consists of seven domains: Identification of Candidacy, Navigation, Permeability of services, Appearances at health services, Adjudications, Offers and resistance, and Operating conditions and the local production of Candidacy (see definitions online supplementary Appendix 1). Due to the complex nature of managing and accessing treatments for chronic conditions such as OA, the Candidacy framework provides an appropriate conceptual lens to conduct this study.

\section{SETTING}

This study took place at an orthopaedic pre-admission clinic at a publicly funded metropolitan tertiary hospital in Melbourne, Victoria. The clinic performs a high volume of TKRs and receives referrals from both metropolitan Melbourne and regional areas in Victoria. Australia's healthcare is delivered in a mixed system with private providers and universal healthcare (Medicare). Residents are entitled to a Medicare rebate for medical treatment through primary care (although practices may choose to charge fees in excess of this) and publicly funded hospitals. Patients who choose to access the public system for TKR will not incur any out-of-pocket medical costs, however, patients require a referral to see a specialist for elective surgery and are unable to self-refer to an orthopaedic surgeon. In contrast, allied health services are usually accessed by patients paying privately out-of-pocket or by third-party coverage. Rebates for access to community based allied health services are limited to five visits per year (for all providers combined) and only available to those that have a GP management plan in place.

\section{PATIENTS AND METHODS}

Purposive sampling was used to explore a wide range of patient perspectives and experiences, initially seeking variation across sex, age, and the participant's history of having previously undergone a contralateral TKR. Patients were eligible to be approached by the researcher (PO) for recruitment if they were over the age of 18, spoke English, had a diagnosis of knee $\mathrm{OA}$ and were on the waiting list for a primary TKR. Patients were ineligible if they required an interpreter or had cognitive impairment preventing them from providing meaningful responses to interview questions. Patients had no previous relationship with the researcher and all patients at the pre-admission clinic see a researcher as standard practice. Eligible patients were invited to take part in a $30 \mathrm{~min}$ face-to-face interview at the orthopaedic clinic or over the telephone at a time convenient to them. All participants completed a written consent form at the time of recruitment and interviewers confirmed consent verbally at the time of interview. Both telephone and face-to-face interviews were offered allowing the greatest level of convenience to the participants, where telephone interviews also allowed potential accessibility or mobility issues in this population to be overcome. Spouses or significant others were welcome to be present in the interview and field notes were taken after each interview.

The researchers anticipated that data saturation would occur by 20 to 25 interviews based on previous research. ${ }^{13-15}$ Therefore, a sample size of 30 was the recruitment target to allow for further testing of themes beyond saturation.

\section{PATIENT AND PUBLIC INVOLVEMENT}

Patients and the public were not involved in the design, conduct or reporting of this research. 


\section{DATA COLLECTION}

Interviews questions were semi-structured and based around on the domains of the Candidacy framework (online supplementary Appendix 1). While the interview schedule was structured on Candidacy, the interviews were semi-structured to allow for any new directions raised by the participants related to the factors impacting on decisions to progress to TKR to be explored. Interviews were carried out by two female researchers ( $\mathrm{PO}$, a research assistant; SB, a post-doctoral researcher), both of whom have extensive experience conducting qualitative interviews.

All interviews were audio-recorded, transcribed verbatim and entered into NVivo 10 (QSR International) for data analysis.

\section{DATA ANALYSIS}

Data analysis was conducted concurrently with data collection to allow for emerging themes in the data to be pursued in future interviews. Transcripts were reviewed and coded by two researchers independently (PO and SB). Using thematic analysis, ${ }^{16}$ the researchers identified codes in the data and mapped these codes to the seven Candidacy domains. For each domain, mapped codes were grouped into themes. A sample of transcripts were coded by additional authors to ensure consistency in coding (JMN and DA). Inconsistencies in coding were settled through consensus discussion among the research team. Members of the multidisciplinary research team, including social scientists, a physiotherapist, and a GP met to discuss the findings of the analytical process and define final themes.

\section{RESULTS}

Between March 2018 and September 2018, 27 participants (14 male and 13 females) with OA were recruited from the pre-admission clinic. The demographic characteristics of participants are described in table 1 . The mean age of participants was 68 years old (age range 52 to 80 years).

Four patients declined participation at the time of recruitment and a further four participants declined when called for interview. Half the participants were undergoing their second TKR and one participant had been consented for bilateral simultaneous TKRs. Twenty-seven semi-structured interviews (7 face-to-face and 21 telephone) were conducted. Interviews lasted for $30 \mathrm{~min}$ on average. No differences in length or content were observed between face-to-face and telephone interviews.

The results are presented for each domain of the Candidacy framework, starting with a description of the domain and followed by the themes identified for each domain. Themes describe participants' experiences of each of the Candidacy domains. Each theme is supported by quotes (eg, Quote 1) which are charted in and can be referred to

\begin{tabular}{ll}
\multicolumn{2}{l}{ Table 1 Participant characteristics } \\
\hline Characteristics & Percentage participants (\%) \\
\hline Sex (female) & 48.1 \\
$\begin{array}{l}\text { Age (years) } \\
50-59\end{array}$ & 14.8 \\
$60-69$ & 40.7 \\
$70-79$ & 40.7 \\
$80+$ & 3.7 \\
BMI (kg/m ${ }^{2}$ ) & \\
$<18.5$ & 0 \\
$18.5-24.9$ & 3.7 \\
$25.0-29.9$ & 37.0 \\
$>30.0$ & 59.3 \\
Contralateral TKR & \\
Yes & 48.1 \\
No & 48.1 \\
Bilateral simultaneous & 3.7 \\
\hline
\end{tabular}

*Totals may exceed $100 \%$ because of rounding.

$\mathrm{BMI}$, body mass index; TKR, total knee replacement.

in table 2. Quotes were selected on the basis of relevance to statements they are supporting within each theme.

\section{Candidacy Domain 1. Identification of Candidacy: "My knee is} sore, I need to do something about it"

Two main themes were identified in this domain: history of knee problems (including change in symptoms) and physical and psychosocial functioning.

\section{History of knee problems, change in symptoms}

Most participants described a long history of knee pain, dating back several years, and in many cases several decades. All described a downward trajectory, a worsening of their symptoms over time. While many described this as a gradual process, some felt they could pinpoint the moment when their symptoms worsened. One participant described the moment that the cartilage in the joint had become so worn that the "bone was catching on bone" resulting in a sudden increase in pain severity (Quote 1 ).

\section{Physical and psychosocial functioning, can't cope anymore}

All participants described reaching a tipping point, the point at which their symptoms were interfering with important and valued life activities and independence, resulting in feelings of frustration (Quote 2). Many, predominantly female participants, also described feelings of fear due to lack of confidence in the strength of the knee and the unpredictable nature of pain (Quote $3)$. In addition to frustration and fear, many participants described low mood and feelings of depression resulting from withdrawal from social and recreational activities (Quote 4). When they arrived at a point that they could no longer cope with the impact of pain on their quality 
Table 2 Summary of themes identified with supporting quotes

\begin{tabular}{|c|c|}
\hline Candidacy domain & Themes \\
\hline $\begin{array}{l}\text { Identification ofCcandidacy } \\
\text { "My knee is sore, I need to } \\
\text { do something about it" }\end{array}$ & $\begin{array}{l}\text { History of knee problems } \\
\text { - Downward trajectory } \\
\text { Physical and psychosocial } \\
\text { functioning } \\
\text { - Can't cope anymore }\end{array}$ \\
\hline
\end{tabular}

\section{Illustrative quotes}

Quote 1: "I felt it just one day. It must have been - seeing what's going on in the photographs - it must have been when the bone started hitting bone on bone because it was just - one day I was walking good, the next day bang. It was giving me a lot of pain but not as much as when you get the bone catching on bone. You can feel it actually grinding" (Interview 19, M, 65).

Quote 2: "Well, I used to be able to do so many things. Now I find I can't do it and it frustrates me. You know, sometimes I like to go out and do a little shopping of my own. Pick up a few things that I like when my daughter is not at home. Fend for myself... I can't" (Interview 5, F, 77 years).

Quote 3: "I'm scared it's going to give way, that's why l've got the crutches - It did 2 days ago when I was out shopping, I was holding onto the bench of a shop and then I couldn't walk, so you become wary" (Interview 9, F, 60 years).

Quote 4: "Yes, I can't go anywhere because I can't enjoy myself. All those sort of things that makes a life worth living" (Interview 13, M, 74 years).

Quote 5: "You know I just need this fixed so I can get my life back" (Interview 26, F, 62 years).

Navigation

"What services can I access for my knee?"
- GP and social networks as information sources

- Access to care (conservative treatments)
Quote 6: "The doctor just recommended - anti-inflammatory tablets, because there's no point - I can't go to physio because it's sore in the knee. I can't walk because it's sore in the knee. So, they sent me for $x$-rays. My doctor said, "I think you need a new knee cap. I think your knee's done"' (Interview 2, M, 79).

Quote 7: "He (GP) didn't really say anything at that point. I hadn't done any physio, he didn't suggest it because he handballed it to... the specialist, first" (Interview 21, F, 52 years).

Quote 8: "Well when I first started getting it, I remember I thought I'd have to be in a wheelchair. But then my sisters told me, or one of them, "Well why don't you go swimming?" And with my knee pain, that helps a lot" (Interview 18, F, 72 years).

Quote 9: "A friend of mine in his 70s... he just had both of them done... and he reckons it's fantastic. I've spoken to quite a few people and it's - when you're in a place that is not very good for being able to do something as simple as walking down the street, any option is a better option than what you've got. I certainly don't think it's going to get better on its own" (Interview 3, M, 63 years).

Quote 10: "Just go to the local GP and see what information...or Google it, mainly Google it just to see what people are doing" (Interview 6, F, 55 years).

Quote 11: "When I had sciatica, they sent me to the pool and I did a class and then I just carried on, on my own, just doing the same exercises as I'd done in the class. But the physio there, I asked her what I could do for my knees and she just told me to do this exercise and that exercise" (Interview 3, M, 63 years).

Quote 12: "Actually (GP) has suggested the pool but there isn't one really close and then it impacts on me financially because I'm not working, I'm on a disability pension, what I can do (is) very frustrating. You're meant to be doing extra things but then you don't have the money to do it, and it's like, well, yeah" (Interview 9, F, 60years). 
Table 2 Continued

\begin{tabular}{ll}
\hline Candidacy domain & Themes \\
\hline $\begin{array}{l}\text { Permeability of services } \\
\text { "How easy is it to access }\end{array}$ & Referral pathway for \\
the services I need?" & surgery is easy/linear \\
& $\begin{array}{l}\text { Referral pathway for } \\
\text { conservative treatment is } \\
\text { unknown and complex }\end{array}$
\end{tabular}

Illustrative quotes

Quote 13: "They haven't really told me what to expect, because it's been so quick a process. I've seen (GP) and I went and saw him to go through to (Hospital) and then I've been on Friday for the pre-admission" (Interview 17, F, 66 years).

Quote 14: "The GP just sent a letter to (Hospital), and that was it. The next thing I heard was from (Hospital), and I went up to do all the tests, and so forth" (Interview 2, M, 79 years).

Quote 15: "I don't know, they offered me some things to do and I couldn't even do it. I said, "I'll do what I can" but no, it didn't work. My knee got worse, actually" (Interview 1, M, 65 years).

Quote 16: "I haven't been going to physios or anything like that... Because they probably don't do much for you, because you've got to do it yourself. You've got to make sure that you do the right thing I suppose. Because that's all - they can't replace my cartilage" (Interview 18, F, 72 years).

Quote 17: "I've decided that a knee replacement thing, and I've just gone along that path. There may be other things out there that are available, I personally can't think of any" (Interview 10, M, 70years).

Appearances at health services

"Can I communicate the pain I am in and the impact it is having on me to the doctors?"
Communication of impact

- Use of pain/opiate medication

Quote 18: "(I said to the GP) Look I can't go on like this. I need something to be done." And so he referred me to the orthopaedic people" (Interview 13, M, 74 years).

Quote 19: "I said to (the surgeon), put me on the general waiting list. I need to have it done. I can't live. I mean, I was on so much Oxycontin, like you wouldn't believe... I was on that for five years and not something I put myself on, my doctor put me on it. And then you get addicted and then you're in all sorts of trouble" (Interview 21, F, 52 years).

Quote 20: "Yeah, I went and saw my doctor, my GP. Had the specialist's name and phone number and I showed it to my doctor and said, "I'd like to see this specialist". And he just said, "Yeah," which is good" (Interview 22, M, 56years).

Quote 21: "I went back and saw him a couple of times. He said try and put it off for as long as you can. He recommended 65 and I sort of, I can't hang on another 10 years, oh my god. So I sort of put it off about two more times" (Interview 6, F, 55 years).

Adjudications

"What do the doctors think I need?"
Predominant health professional referral pathway GP-Surgeon

- Communication

- Comorbidities and age
Quote 22: "I went to see my doctor and they sent a letter off to (Hospital 1) and (Hospital 2), and (Hospital 2) were the quickest. They took me in and it was all done in about five or 6 weeks" (Interview 2, M, 79 years).

Quote 23: "I don't even talk to the GP about the knee anymore, because they can't do nothing for me. I just get the referrals" (Interview 1, M, 65 years).

Quote 24: "I think there should be more consultation between the surgeon and your doctor. Prior to surgery and after surgery. At one point (the surgeon) mentioned about having steroid injections. My GP never mentioned it, I didn't want to go down that path because she was just saying that. Now if that's something that she thought might have worked, maybe that's something that should have been passed onto to my GP from her, saying, "These are some avenues that we can look at." Trying to resolve this at the moment, before going to surgery. There doesn't seem to be that kind of communication, just, "Oh, we went in, we found this and that's what it is." End of story, just like a diagnosis" (Interview 21, F 52 years).

Quote 25: "Everything else, we've ticked the box, but l've got a slight mark on the back of my leg, which my doctor thinks it might be a melanoma, and I have to get a biopsy on it. I'm getting that done tomorrow. They only rang me up today to tell me that, yes, the operation's okay if I find out what's on the back of my leg and get it fixed" (Interview 4, M, 77 years).

Quote 26: "I've just been putting up with pain, just waiting - because virtually the doctors say I'm too young. But everyone in my family don't live until - they all die before 70 . So, what, am I going to live for the rest of my life in pain? My way of thinking about it is get it done, get on with life so I can get back to work. I want to work" (Interview 19, M, 65 years). 
Table 2 Continued

\begin{tabular}{ll}
\hline Candidacy domain & Themes \\
\hline Offers and resistance & Pain and physical activity
\end{tabular}
doctors say I should do?"

Illustrative quotes

Quote 27: "No, not really, early on we tried - I tried walking and things like that, even getting on the exercise bike, but it got to the stage where it was just too painful" (Interview 10, M, 70 years).

Quote 28: "It felt good at the time. But, after an hour, I was just back to square one. I thought, "I'm wasting the physio's time and I'm wasting my time," because it cures me for a couple of hours, and then, I'm back to square one...l just stopped going back" (Interview 2, M, 79 years).

Quote 29: "Well she gave me exercises to do and everything like that, and I said, "Look, it's not doing anything, and it's actually made it worse aggravated it" (Interview 1, M, 65 years).

Quote 30: "Not really. Even attempting to walk any wee distance is a lot of work. But, nothing else has - I mean, the doctor wanted me to try riding a bike. What the hell am I riding a bike for? It's worse than the pain in my kneecap!" (Interview 2, M, 79 years).

Quote 31: "Well, to me what's the point in trying to do something when something's worn out? I believe in nuts and bolts and if something's worn out you pull it out and put a new part in" (Interview 19, M, 65years).

Quote 32: "I go to the pool every morning. I go to the pool every morning and I walk in the pool and that really helps to keep it moving and keep the muscles warm. So, it does help" (Interview 25, M, 64 years).

Quote 33: "(CrossFit) 3 days a week. And then the riding l've been doing as well so even if I'm not going on social rides I ride to the shops or things like that, I ride to CrossFit, that's $11 \mathrm{~km}$ round trip" (Interview 7, F, 66 years).

\begin{tabular}{|c|c|c|}
\hline $\begin{array}{l}\text { Operating conditions and } \\
\text { the local production of } \\
\text { Candidacy } \\
\text { "I've decided to have a } \\
\text { TKR, } \\
\text { When and where can I have } \\
\text { it done?" }\end{array}$ & $\begin{array}{l}\text { Familiarity with local } \\
\text { system } \\
\text { Availability }\end{array}$ & $\begin{array}{l}\text { Quote 34: "I was very happy with the care and the treatment I received } \\
\text { from those people. I think all the nurses and the doctors, the specialist } \\
\text { there, they spoke very confidently to me and to tell me the position I was } \\
\text { in and what they're going to do. So I felt very at ease. And knowing I'm } \\
\text { in professional hands and those people know exactly what they're doing" } \\
\text { (Interview 25, M, } 64 \text { years). } \\
\text { Quote 35: "Oh well it's partly because I've had one already and I know } \\
\text { that it made a huge difference... So it's probably an easier decision when } \\
\text { you've already been there and done that" (Interview 8, F, } 66 \text { years). } \\
\text { Quote 36: "I was waiting and waiting for my name to come up I just felt } \\
\text { that my life was on hold and I couldn't plan anything" (Interview } 12, \mathrm{~F}, 75) \text {. } \\
\text { Quote 37: "Look, if it can be improved I'll be happy about it but the } \\
\text { thing is I don't know the capacity of how many people a year, how } \\
\text { much surgeries a year, how much operations they're having. So, I } \\
\text { can understand that sometimes they have to put you back a little bit" } \\
\text { (Interview 25, M, } 64 \text { years). }\end{array}$ \\
\hline
\end{tabular}

GP, general practitioners; TKR, total knee replacement.

of life and emotional well-being, they sought treatment to "get their life back" (Quote 5).

\section{Candidacy Domain 2. Navigation: "What services can I access for my knee?"}

Two main themes were related to Navigation: GP and social networks as information sources and access to care.

\section{GP and social networks as information sources}

For almost all participants, their GP was the primary source of information about management options. According to participants, GPs most commonly recommended pharmacological interventions as well as complementary medicine (eg, fish oil) to control symptoms. Following imaging, GPs were reportedly quick to "handball to specialists" (Quote 6). According to most participants, GPs provided little information about more active interventions such as exercise or physiotherapy (Quote
7). Instead, advice regarding exercise or physiotherapy often came from social networks (Quote 8) or the internet (Quote 9). Social networks were also an important source of information for TKRs (Quote 10).

Interestingly, allied health professionals were not identified as important sources of information for participants, even if they had engaged in non-surgical interventions such as physiotherapy. Only one participant stated that they had asked their physiotherapist about exercises for their knee OA while seeing them for an alternative health issue (Quote 11).

\section{Access to care}

Participants did not often identify practical barriers to accessing non-surgical interventions; although this may be because they were not offered them in the first place. Two participants identified transport and finances as a 
barrier to them being able to access allied health on an ongoing basis (Quote 12).

\section{Candidacy Domain 3. Permeability of services: "How easy is it to access the services I need?"}

One main theme was identified when considering the permeability of services: Ease of referral pathway, with TKR being linear and simple, and non-surgical interventions being complex and unknown.

Referral pathway for surgery is easy and linear, while the pathway for non-surgical interventions is unknown and complex

Despite requiring a referral from a doctor to see an orthopaedic surgeon, all participants described the process as easy (Quote 13). Irrespective of being referred by their GP or another health professional (eg, rheumatologist, pain management specialist), the pathway in the public system was clear to participants, often with all appointments and navigation being facilitated by health professionals (Quote 14). In contrast, among those that were recommended non-surgical interventions by their health professionals, some expressed uncertainty about how the treatment would help them, what would be expected of them (Quote 15), and their capacity to engage in those activities due to experiencing pain (Quote 16). In addition to finding it difficult to navigate non-surgical interventions, some participants had already made their mind up to "go down the surgery path" (Quote 17).

\section{Candidacy Domain 4. Appearance at health services: "Can I communicate the pain I am in and the impact it is having on me to the doctors?"}

The main theme identified for this domain was communication of impact.

\section{Communication of impact}

The majority of participants were able to communicate to health professionals the significant impact that $\mathrm{OA}$ was having on their quality of life (Quote 18). Many were able to present their case for Candidacy through their ability to express negative attitudes towards their need to use multiple strong pain medications, especially their concern with ongoing opiate use which signified their need for greater intervention (Quote 19).

Participants often demonstrated volition in their ability to directly ask GPs for a referral to a specialist or orthopaedic surgeon (Quote 20), facilitating access to TKR. However, several participants expressed frustration at being told by health professionals to "just bear with" their increasingly disabling pain, often because they were "too young” for a TKR (Quote 21).

\section{Candidacy Domain 5. Adjudications: "What do the doctors think I need?"}

The main theme for this domain was the GP-Surgeon pathway as predominant health professional referral pathway.
Predominant health professional referral pathway GP-surgeon The most common adjudication for GPs to make was that surgery was a necessary treatment, reflected in the referrals made to orthopaedic surgeons (Quote 22). GP referrals to surgeons meant that potential opportunities to discuss non-surgical interventions were bypassed (Quote 23). One participant also described poor communication between surgeons and GPs as a missed opportunity for health professionals to make collaborative adjudications, therefore being a barrier to engaging in non-surgical interventions (Quote 24).

Health professional adjudications were also impacted by participants' experience of comorbidities, which often led to the wait time for surgery to be extended (Quote 25). Participants' age also appeared to influence health professionals' adjudications of Candidacy for a TKR (Quote 26).

Candidacy Domain 6. Offers and resistance: "Should I do what the doctors say I should do?"

The main themes identified as reasons participants refused offers of non-surgical interventions were the experience of physical activity as painful, and beliefs about the effectiveness of non-surgical interventions.

\section{Physical activity as painful}

Many participants who had tried an exercise based non-surgical intervention recommended by their health professionals found them too painful to engage in longterm (Quote 27) or found that they aggravated their symptoms (Quote 28) and were thus a "waste of their time" (Quote 29). Some participants refused offers involving exercise altogether (Quote 30).

\section{Beliefs about effectiveness of non-surgical interventions}

Participants' commonly perceived that non-surgical interventions were "Band-Aid fixes" that could not repair the damage in their knee. Surgery was perceived as the "only true blue fix", and thus inevitable (Quote 31). While several participants were actively engaged in exercise to manage their pain (Quote 32), these were typically participants who described being highly active in the past (Quote 33).

\section{Candidacy Domain 7. Operating conditions and the local} production of Candidacy: "I've decided to have a TKR, when and where can I have it done?"

Two main themes were identified for this domain: Familiarity with the local system and availability.

\section{Familiarity with the local system}

The majority of participants demonstrated familiarity with the local system, often a result of experiencing comorbid conditions requiring ongoing contact with the system or previous experience of a TKR. Having previous interactions with the local system led to widespread trust in the institution and their healthcare professionals (Quote 34). Participants who had previously undergone a TKR often expressed that they knew what to expect which further 
confirmed their suitability for surgery. Having "been there and done that" made the decision to have a second knee done "easier" (Quote 35).

\section{Availability}

Participants had varying views on the availability of surgery. Many found the wait time for their surgery frustrating, mainly because the uncertainty of the prospective date led to feeling as though their "life was on hold" or that they were "running out of time". This uncertainty led a participant to take herself off the waiting list at one point (Quote 36). Alternatively, some participants expressed gratitude towards Australia's publicly funded health system and were therefore understanding and accepting of their wait times (Quote 37).

\section{DISCUSSION}

In this study we have identified patient factors that impact on decision-making to undergo TKR in an Australian context, including the experience of patients in general practice, their perceptions of their condition and their access and use of community-based allied health interventions or non-surgical interventions. We have also highlighted a number of organisational, clinician and patient-related factors that acted as barriers and facilitators to accessing non-surgical community-based treatments and TKRs, respectively.

The participants in this study most frequently reported being referred to specialists and orthopaedic surgeons. This is consistent with national data showing that the rate of GP referral to orthopaedic surgeons is 11.9 per 100 contacts compared with referral to physiotherapy, 3.2 per 100 contacts. $^{2}$ This may reflect the perception among GPs that TKR is the ultimate and only effective treatment for knee $\mathrm{OA},{ }^{17}$ a perception also articulated by the participants in this study and reinforced by information they had received from their social networks. GP referrals to surgeons increase the permeability and likelihood of accessing a TKR. Based on the participants' narratives, the clinical pathway between GP and TKR appeared to be the pathway of least resistance. Indeed, in Australia, the GP sends the referral to the relevant hospital department, appointments are facilitated by the health service and then provided to the patient. In contrast, GP referrals to allied health usually require the patient to choose a provider and make their own appointments.

By accessing the public hospital system for TKR, the participants in this study incurred no out-of-pocket medical costs. This is also likely to facilitate uptake of TKR. In contrast, only some patients on chronic disease plans are able to access up to five allied health visits per year, which are often only partially funded by Australia's public system. ${ }^{18}$ Given the comorbidity profile of people who experience $\mathrm{OA}$ and the multidisciplinary care required, this may be insufficient. Despite the limited accessibility and associated cost of accessing allied health services in Australia, participants in this study did not often volunteer cost as a barrier to accessing non-surgical interventions. GPs may be reluctant to refer patients to allied health due to the associated costs and knowing that their patients may be unable to pay for such services. ${ }^{19-21}$

According to participants, pharmacological interventions were also commonly recommended by GPs. Although participants showed a willingness to use medication to treat their knee pain instead of activity-based interventions, they also expressed concern about long-term opiate use. The Royal Australian College of General Practitioners Guideline for the management of knee and hip OA (RACGP OA) strongly recommends against the use of oral and transdermal opioids for the management of knee OA. The proportion of participants who were using opioid medication to manage their knee pain warrants further investigation into the prescribing patterns of GPs for knee OA in the community.

The RACGP OA also recommends land-based exercise for all people with knee OA, regardless of their age, disease severity, functional status or pain levels, with TKR reserved for people who have exhausted non-surgical options. ${ }^{5}$ Despite the RACGP OA being available to clinicians, there is evidence suggesting that many GPs are unaware of these guidelines, ${ }^{21}$ and uptake of clinical guidelines is often poor. ${ }^{22-24}$ Participants in this study reported a lack of offers and information being provided to them about such non-surgical interventions. There is a strong imperative to improve the uptake of non-surgical interventions for OA. Approximately one-quarter of the 60000 TKRs currently performed in Australia annually do not meet evidence-based criteria for TKR, and $12 \%$ to $20 \%$ of people who undergo this surgery do not benefit. ${ }^{25-28}$ At least $\$ 158$ million is thus spent on surgery which leads to no clinically meaningful benefit. ${ }^{29}$ This unnecessarily places people with knee OA at risk of harm, including 1 in 11 experiencing adverse events such as thromboembolism, myocardial infarction, and death. ${ }^{30} 31$ The trend for increasing numbers of TKR continues with a $10 \%$ increase observed from 2013 to 2014 alone.$^{32}$ Further, research has shown that three-quarters of people on surgical waiting lists who are offered exercise therapy delay their decision to progress to surgery by at least 12 months. ${ }^{31}$ However, such therapy is rarely provided before undergoing TKR, ${ }^{33}$ even in the presence of long waitlists. ${ }^{34}$

GPs are an important source of information for patients with knee OA. Working out the best way to get the latest evidence-based guidance to GPs and their patients is vital and will require more than issuing guidelines. Decision support tools and patient support materials will all be required for patients to successfully engage in recommended first-line therapies. Providing formal, written information may help promote the benefits of exercise, reassure patients that exercise is not harmful and clarify the prognosis of knee OA so that patients understand that multiple trajectories exist for OA. The findings of this study will contribute to the development of a programme of work seeking to design a clinical prediction tool to be used in the GP setting. 


\section{Strengths and limitations}

The qualitative design of this study enabled us to gain an understanding of the experience of knee OA in general practice as well as patient factors relating to decision-making for TKR and non-surgical management strategies. Strengths of the study included robust recruitment strategies enabling the researchers to reach data saturation. While this study is in an Australian context, similar findings in relation to patient decision-making for TKR have been seen in other healthcare contexts. ${ }^{7}$ Overlapping themes such as coping, pain and function, psychological implications, previous experience of surgery, and the important role of social networks suggest that the results of our study are consistent with international literature. ${ }^{7}$ The study also utilised the Candidacy framework to provide a conceptual lens to understand healthcare access from the beginning of the study. We have demonstrated that the Candidacy framework is useful for describing healthcare access for complex chronic health conditions and that the framework can be adapted for use in samples beyond that of vulnerable groups for which it was originally designed.

Limitations of this study include only recruiting patients attending a metropolitan public hospital who had been consented to proceed to TKR. Therefore, the study findings may not be reflective of the experience of people with $\mathrm{OA}$ in the community who have not yet considered surgical intervention, or with lower levels of health literacy. Half of the participants in this study were also undergoing their second TKR. As expected, familiarity with the referral process and "knowing what to expect" meant these participants perceived access to TKR as "easy". However, similar themes related to all seven domains were identified between people undergoing their first and second TKR suggesting that, while the experience of a previous TKR may have facilitated access, the social influences underlying access remained consistent. Future prospective qualitative studies following along the journey of their knee OA would be valuable, as would interviewing health professionals to understand their perspectives on factors influencing the patient journey. Future qualitative studies in other healthcare systems would be useful to contrast and compare the experiences we have observed among this Australian sample.

\section{CONCLUSION}

Using the Candidacy framework to analyse patients' experiences when deciding to progress to TKR highlighted missed opportunities in general practice to orient patients to first try non-surgical interventions. GPs are the gatekeepers to care and are well placed to provide information about the benefits of non-surgical interventions for knee OA. There is an opportunity for the development of resources and decision-making tools to assist GPs in providing this information. This would support shared decision-making for the trial of non-surgical intervention prior to surgery, which is likely to improve patient outcomes even when surgery is required. System level and patient-related barriers should also be considered in the development of models of care for knee OA to ensure that only the most appropriate candidates are referred to surgery.

Acknowledgements The authors would like to thank patients who participated in this research.

Contributors JMN devised the study and JMN, MD, SB, PO, DA and JG contributed to the study design. $\mathrm{PO}$ and $\mathrm{SB}$ conducted the interviews and performed the analysis of the data with input from JMN and DA. PO drafted the manuscript. All authors revised all drafts and approved the final version of the manuscript.

Funding Research reported in this publication was funded and supported through the NHMRC Centre for Research Excellence in Total Joint Replacement (APP1116235), awarded to the University of Melbourne, Department of Surgery and St. Vincent's Hospital. A/Professor Michelle Dowsey is supported by an NHMRC Career Development Fellowship (APP1122526).

Competing interests None declared.

Patient consent for publication Not required.

Ethics approval Ethics approval was granted by St Vincent's Hospital Melbourne Human Research Ethics Committee (HREC/18/SVHM/23) and registered with The University of Melbourne Human Research Ethics Committee (HREC ID 1851154). All participants gave informed consent to participate in the study.

Provenance and peer review Not commissioned; externally peer reviewed. Data availability statement Data are available upon reasonable request.

Open access This is an open access article distributed in accordance with the Creative Commons Attribution Non Commercial (CC BY-NC 4.0) license, which permits others to distribute, remix, adapt, build upon this work non-commercially, and license their derivative works on different terms, provided the original work is properly cited, appropriate credit is given, any changes made indicated, and the use is non-commercial. See: http://creativecommons.org/licenses/by-nc/4.0/.

\section{REFERENCES}

1. Australian Institute of Health and Welfare. Australia's health 2016. Australia's health series no. 15. Cat. no. AUS 199. Canberra: AlHW, 2016.

2. Brand CA, Harrison C, Tropea J, et al. Management of osteoarthritis in general practice in Australia. Arthritis Care Res 2014;66:551-8.

3. Harrison C, Henderson J, Miller G, et al. The prevalence of diagnosed chronic conditions and multimorbidity in Australia: a method for estimating population prevalence from general practice patient encounter data. PLoS One 2017;12:e0172935.

4. Cross M, Smith E, Hoy D, et al. The global burden of hip and knee osteoarthritis: estimates from the global burden of disease 2010 study. Ann Rheum Dis 2014;73:1323-30.

5. The Royal Australian College of General Practitioners. Guideline for the management of knee and hip osteoarthritis. 2nd edn. East Melbourne, Victoria: RACGP, 2018.

6. McHugh GA, Campbell M, Luker KA. Quality of care for individuals with osteoarthritis: a longitudinal study. J Eval Clin Pract 2012;18:534-41.

7. Barlow T, Griffin D, Barlow D, et al. Patients' decision making in total knee arthroplasty. Bone Joint Res 2015;4:163-9.

8. Dowsey MM, Gunn J, Choong PFM. Selecting those to refer for joint replacement: who will likely benefit and who will not? Best Pract Res Clin Rheumatol 2014;28:157-71.

9. Ritchie J, Spencer L, O'Connor W. Carrying out qualitative analysis. In: Ritchie J, Lewis J, eds. Qualitative research practice: a guide for social science students and researchers. London: SAGE Publications Ltd, 2003: 219-62.

10. Dixon-Woods M, Cavers D, Agarwal S, et al. Conducting a critical interpretive synthesis of the literature on access to healthcare by vulnerable groups. BMC Med Res Methodol 2006;6:35.

11. Tookey S, Renzi C, Waller J, et al. Using the candidacy framework to understand how doctor-patient interactions influence perceived eligibility to seek help for cancer alarm symptoms: a qualitative interview study. BMC Health Serv Res 2018;18:937.

12. Methley A, Campbell S, Cheraghi-Sohi S, et al. The value of the theoretical framework of candidacy in exploring access 
and experiences of healthcare services. Health Psychol Update 2016;25:1-11.

13. Chan KKW, Chan LWY. A qualitative study on patients with knee osteoarthritis to evaluate the influence of different pain patterns on patients' quality of life and to find out patients' interpretation and coping strategies for the disease. Rheumatol Rep 2011;3.

14. Gay C, Eschalier B, Levyckyj C, et al. Motivators for and barriers to physical activity in people with knee osteoarthritis: a qualitative study. Joint Bone Spine 2018;85:481-6.

15. Nyvang J, Hedström M, Gleissman SA. It's not just a knee, but a whole life: a qualitative descriptive study on patients' experiences of living with knee osteoarthritis and their expectations for knee arthroplasty. Int J Qual Stud Health Well-being 2016;11:30193.

16. Braun V, Clarke V. Using thematic analysis in psychology. Qual Res Psychol 2006;3:77-101.

17. Alami S, Boutron I, Desjeux D, et al. Patients' and practitioners views of knee osteoarthritis and its management: a qualitative interview study. PLoS One 2011;6:e19634.

18. Australian Institute of Health and Welfare. Patients' out-of-pocket spending on Medicare services, 2016-2017. Canberra: AlHW, 2018.

19. Cott CA, Devitt RMA, Falter L-B, et al. Barriers to rehabilitation in primary health care in Ontario: funding and wait times for physical therapy services. Physiotherapy Canada 2007;59:173-83.

20. Davis AM, Palaganas M, Li LC. Public opinion on communitybased education and exercise programs for managing hip and knee osteoarthritis-like symptoms: results of a survey. Patient Prefer Adherence 2016;10:283-90.

21. Arthritis Australia. Whose problem is it anyway? the voice of GPs on arthritis. arthritis Australia, 2012.

22. Fischer F, Lange K, Klose K. Barriers and strategies in quideline implementation-a scoping review. healthcare. Multidisciplinary Digital Publishing Institute, 2016.
23. Keiffer MR. Utilization of clinical practice guidelines: barriers and facilitators. Nurs Clin North Am 2015;50:327-45.

24. Doherty S. Evidence-based implementation of evidence-based guidelines. Int J Health Care Qual Assur 2006;19:32-41.

25. Ferket BS, Feldman Z, Zhou J, et al. Impact of total knee replacement practice: cost effectiveness analysis of data from the osteoarthritis initiative. BMJ 2017;356.

26. Australian Orthopaedic Association National Joint Replacement Registry (AOANJRR). Hip, Knee \& Shoulder Arthroplasty: 2017 Annual Report. Adelaide: AOA, 2017.

27. Quintana JM, Escobar A, Arostegui I, et al. Health-Related quality of life and appropriateness of knee or hip joint replacement. Arch Intern Med 2006;166:220-6.

28. Alzahrani K, Gandhi R, deBEER J, et al. Prevalence of clinically significant improvement following total knee replacement. $J$ Rheumatol 2011;38:753-9.

29. Dowsey MM, Liew D, Choong PFM. Economic burden of obesity in primary total knee arthroplasty. Arthritis Care Res 2011;63:1375-81.

30. Liddle AD, Judge A, Pandit $\mathrm{H}$, et al. Adverse outcomes after total and unicompartmental knee replacement in 101330 matched patients: a study of data from the National Joint Registry for England and Wales. The Lancet 2014;384:1437-45.

31. Skou ST, Roos EM, Laursen MB, et al. A randomized, controlled trial of total knee replacement. N Engl J Med 2015;373:1597-606.

32. Australian Orthopaedic Association Joint Replacement Registry. Hip and knee arthroplasty. Adelaide: AOA, 2015.

33. Wallis JA, Taylor NF. Pre-operative interventions (non-surgical and non-pharmacological) for patients with hip or knee osteoarthritis awaiting joint replacement surgery--a systematic review and metaanalysis. Osteoarthritis Cartilage 2011;19:1381-95.

34. Australian Institute of Health and Welfare. Elective surgery waiting times 2015-16: Australian hospital statistics. health services series No. 73. cat. No. HSE 183. Canberra: AlHW, 2016. 